\title{
Epidemiological Study of Cutaneous Malignant Melanoma in Shiraz, Southwest of Iran between 2011 and 2016
}

\author{
Elaheh Shaghaghian ${ }^{1}$, Mohammad Reza Namazi ${ }^{2}$ \& Alireza Shaghaghian ${ }^{3}$ \\ ${ }^{1}$ Student Research Committee of Shiraz University of Medical Sciences, Shiraz, Iran \\ ${ }^{2}$ Dermatology Department, School of Medicine, Shiraz University of Medical Sciences, Shiraz, Iran \\ ${ }^{3}$ Kowsar Hospital, Shiraz, Iran \\ Correspondence: Elaheh Shaghaghian, Student Research Committee of Shiraz University of Medical Sciences, \\ Shiraz, Iran. E-mail: elahehshaghaghian@gmail.com
}

Received: May 22, 2019

Accepted: September 24, 2019

Online Published: October 23, 2019

doi:10.5539/jmbr.v9n1p106

URL: https://doi.org/10.5539/jmbr.v9n1p106

\begin{abstract}
Background: Melanoma is the most deadly of all skin cancers in the world, its incidence rate has increased in the last decades. We aim to define the frequency, and epidemiologic features of Cutaneous Malignant Melanoma Cases diagnosed between 2011 and 2016 in teaching hospitals of Shiraz University of Medical Sciences, southwest of Iran.

Materials and Methods: This descriptive cross-sectional study was have performed at hospitals affiliated with Shiraz University of Medical Sciences from 2011 to 2016. Pathology reports collected from the laboratory along with general information such as age, sex, site of the tumor and had ulceration or not. SPSS version 23 statistical software was used for data analyzing. P-values less than 0.05 were considered significant.

Results: A total of 183 cases of Cutaneous Malignant Melanoma were registered in Faghihi Teaching hospital, 7 cases in Namazi Teaching Hospital and 6 cases in Motahari clinic in Shiraz, between 2011 and 2016. The average age was 64.5 years with age range of 1year to 89 years, mostly in women $(51.5 \%)$ and also most of the tumor sites were in the foot $46(23.5 \%)$ and then in the scalp $20(10.2 \%)$. The incidence of ulceration was 41 $(20.9 \%)$, and the most common stage of the tumor was stage one.

Conclusion: The results proved the importance of awareness of the physicians about the frequency and epidemiologic features of Cutaneous Malignant Melanoma in their region that they can diagnose or screen and treat them more earlier in better ways.
\end{abstract}

Keywords: Epidemiology, Melanoma, Iran

\section{Introduction}

Skin as the largest living member of the body, in fact, it is also considered as one of the most complex, most interesting and most prolific member (Hamed Alharbi, Mousa, Alrashidi, Alighadaf, \& Aljohani, 2018). Cancer is the uncontrolled proliferation of abnormal cells that leads to a malignant growth, and ultimately severe morbidity and mortality (Alshammari, 2018). Cancer has been one of the causes of morbidity and mortality worldwide (Sholih et al., 2019), and it has been a major threat to mankind, and it kills many people every year (Shrihari, 2018). Skin cancer is the third most popular malignancy in the world. It can be of two types: Non-Melanoma and Melanoma. Malignant Melanoma is the most deadly of all skin cancers (Ferdosi et al., 2016; Razi, Rafiemanesh, Ghoncheh, Khani, \& Salehiniya, 2015), and its Incidence has been increasing globally in past decades. (Ahmadi, Asadi-Lari, Amani, Saeid, \& Solaymani-Dodaran, 2015) It is an increasingly common cancer of melanocytes that mostly arises in the skin or mucosal surfaces, and it is curable with early detection. (Kumar, Abbas, \& Aster, 2015; Natalie \& Wen-Qing, 2017) The underlying causes are not known yet, although host and environmental are the most important factors such as exposure to ultraviolet radiation and geographic localization, family history of melanoma, immunosuppression and also, type 2 of diabetes mellitus slightly increase the risk of developing Melanoma. (Moslehi, Zeinomar, \& Boscoe, 2018; Allam, Serrano, Serrano, Abd Elaziz, Del Castillo, \& Navajas, 2015; Qi et al., 2014; Rahnama, Meymandi, \& Nasiri, 2010) Important warning signs are: 1 . asymmetry 2 . irregular borders 3 . variegated color 4 . increasing diameter 5 millimeters 5 . evolution or change over time. (Habif, 2011) Skin biopsy should be done for all suspected patients, and they should have a careful follow up for early detection of new tumors or metastasis (Natalie \& Wen-Qing, 2017). The metastatic 
spread of tumor cells is a complex multistep process (Zavarei, 2018). The treatment is the combination of immunotherapeutics, and radiation and also Melanoma inhibitory activity (MIA) has been used to monitor therapy and to detect early recurrence and metastasis. (Natalie \& Wen-Qing, 2017; Odashiro et al., 2015) The total number of lymph nodes involved in metastasis are important for survival rate. (F. Guarneri \& R. Guarneri, 2014) Findings in such cities of Iran like Yazd, Kerman, Fars, and Kurdistan shows that most of the cases of malignant melanoma are men and mostly it peaks at the 6th decade of life. But we have so many different locations for this cancer, for instance, most common site for people in Yazd (a city in the center of Iran) were head and neck but in Fars the most common site was the foot. Also, findings in Kurdistan shows that the rate of survival for patients was low (50\% for three years) and it is very different from Europe, Unites States (70-86\% for five years) or even other cities of Iran like Yazd (Ahmadi, Asadi-Lari, Amani, Saeid, \& Solaymani-Dodaran, 2015; Rahnama, Meymandi, \& Nasiri, 2010; M. T. Noorbala, Mohammadi, \& M. Noorbala, 2013; Masoompour, Yarmohammadi, Rezaianzadeh, \& Lankarani, 2011; Hanjani et al., 2016).

The most common countries in malignant melanoma are New Zealand, Australia, Switzerland, Netherlands that its incidence rates were 35.8 in 100,000 cases to 19.4 in 100,000. The incidence rate in Africans and Asians were very lower than the other countries and, it is about 4 in 100,000. (Natalie \& Wen-Qing, 2017) The incidence rate of melanoma in people who were born in Australia but their parents were Asians or Africans does not change and, this may show that genetic factors are so important in melanoma. (Czarnecki, 2014) Using personal care products requires national and global safety regulations (Hassanpour, Mahmoudvand, \& Roueintan, 2018). Besides the globally increase the incidence of Malignant Melanoma and previous research in Iran, we aim to define the better frequency and epidemiologic features of Cutaneous Malignant Melanoma cases during a 6- year period in Shiraz south-west of Iran.

\section{Materials and Methods}

This descriptive cross-sectional study was carried out on 196 patients. In the department of dermatology Faghihi Teaching Hospital and Motahari Clinic of Shiraz and Namazi Teaching Hospital of Shiraz, southwest of Iran between 2011 and 2016. Melanoma cases diagnosed by pathologists that use standard criteria. The reports collected along with general information such as age, sex, site, type, depth of invasion. Data were described and then analyzed by a statistician. SPSS version 23 statistical software was used. Chi-square was used to evaluate for statistical significance. P-values less than 0.05 were considered significant.

\section{Results}

During the study period (2011-2016), 183 cases diagnosed in Faghihi Teaching Hospital of Shiraz, 7 cases in Namazi Teaching Hospital and 6 cases of Motahari Clinic that registered in 2011-2016. The age range was 1year to 89 years with an average age of 64.5 years (Figure 2), and also it was most common in women $101(51.5 \%)$ than men 95 (48.5\%). The most frequent lesion sites were foot 46 (23.5\%), and then scalp 20 (10.2\%). (Table 1) Ulcerative lesions incidence was 41 (20.9\%). The most common stage of Malignant Melanoma was stage1 that was $101(51.5 \%)$. (Figure 3) The frequency of melanoma has an increase after the year 2011, and it became about four folds more in the last 2016! (Figure 1)

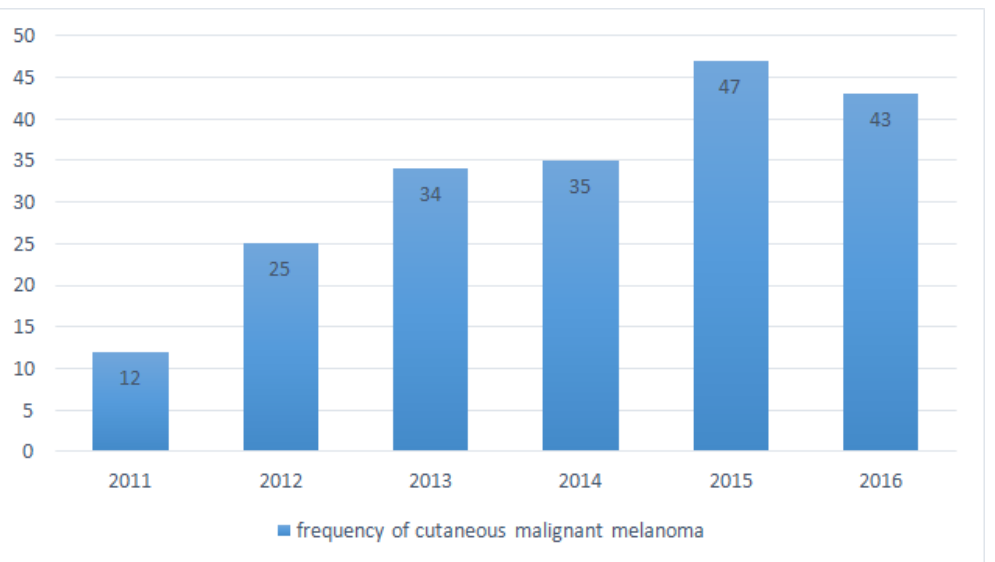

Figure 1. Frequency distribution of Cutaneous Malignant Melanoma between 2011-2016 
Table 1. Frequency distribution according to the location of cancer on the body between 2011-2016

\begin{tabular}{lll}
\hline The site of the skin cancer & Frequency & Percent \\
\hline anal & 4 & 2.04 \\
back & 11 & 5.61 \\
conjunctiva & 1 & 0.51 \\
ear & 3 & 1.53 \\
face & 17 & 8.67 \\
finger & 10 & 5.10 \\
flank & 1 & 0.51 \\
foot & 46 & 23.46 \\
hand & 7 & 3.57 \\
heel & 22 & 11.22 \\
Lymph node axillary & 7 & 3.57 \\
Lymph node inguinal & 19 & 9.69 \\
nail & 8 & 4.08 \\
neck & 3 & 1.53 \\
nose & 5 & 2.55 \\
scalp & 20 & 10.20 \\
shoulder & 4 & 2.04 \\
toe & 8 & 4.08 \\
\hline
\end{tabular}

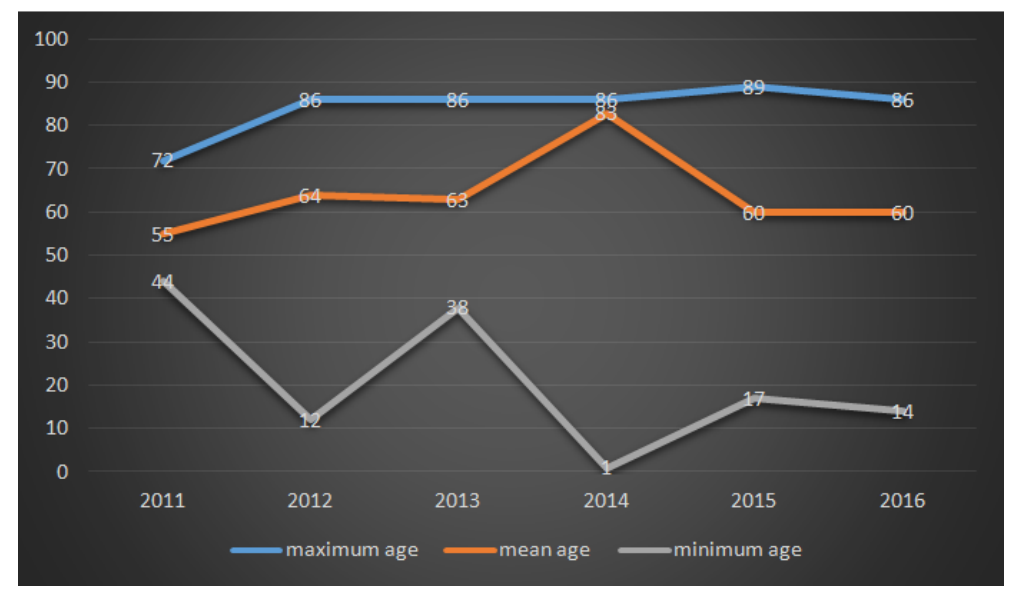

Figure 2. Frequency distribution according to the Age of Cutaneous Malignant Melanoma between 2011-2016

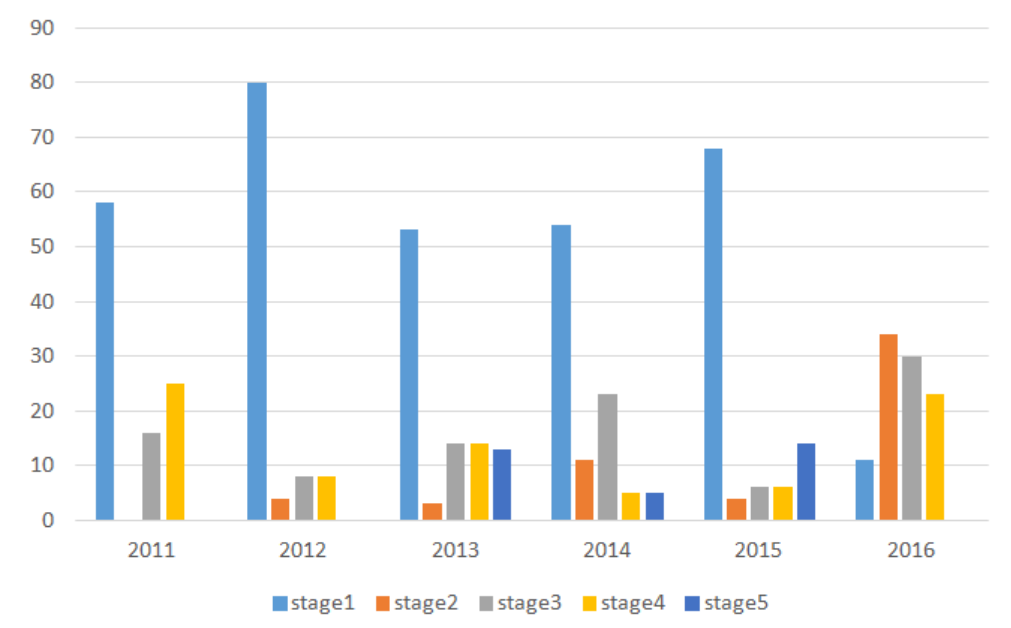

Figure 3. Frequency distribution according to the stages of the Cutaneous Malignant Melanoma between 2011-2016 


\section{Discussion}

The incidence of Cutaneous Malignant Melanoma had been increased In Iran like other countries during the last decade. The age range of Melanoma has been increased and mean age peaks at the 6th decades like other countries. However, the site of Malignant Melanoma in Shiraz is the foot and then the scalp, in Australia the most common site of Melanoma is head and neck that is so different from the Shiraz region. In the current study, we can see in the last three years the stages of the Malignant Melanoma among patients have changed and most of the patients have Cutaneous Malignant Melanoma in higher stages and also the incidence of the Melanoma with the ulcer is more than before. It can be concluded that in spite of increasing the mean age of the patients, we have more cases in age lower than 20years and the minimum age was changed from 44 to 14 years old. However the incidence of this skin cancer is not as much in the world, but we should be careful about the increasing rate of this lethal cancer. As a study proved in 1992 to 2013 the incidence of Malignant Melanoma was 116 cases for 32 years but we can see in our study the incidence of Malignant Melanoma after the year 2013, we have 159 cases during just four years as the same region! So it needs a fast preventive action for handling this lethal cancer! The results of the study offer the insight to the frequency and epidemiologic features of Cutaneous Malignant Melanoma among the population of Shiraz south-west of Iran in the last six years.

\section{Acknowledgement}

The present article was extracted from the thesis written by Elaheh Shaghaghian and was financially supported by Shiraz University of Medical Sciences grants number 11699.

\section{Conflict of interests}

The authors declare that there is no conflict of interests regarding the publication of this paper.

\section{References}

Ahmadi, G., Asadi-Lari, M., Amani, S., Saeid, A., \& Solaymani-Dodaran, M. (2015). Survival from skin cancer andits associated factors in Kurdistan province of Iran. Med J Islam Repub Iran, 29, 277.

Allam, M. F., Serrano, P. F., Serrano, J. L., Abd Elaziz, K. M., Del Castillo, A. S., \& Navajas, R. F. (2015). Cutaneous malignant melanoma, Hodgkin's lymphoma and Non-Hodgkin's lymphoma: Common risk factors? Cent Eur J Public Health, 23(2), 119-12.

Alshammari, F. D. (2018). Do Non-Viral Microorganisms Play a Role in the Aetiology of Human Cancers? A Review. International Journal of Pharmaceutical Research \& Allied Sciences, 7(4), 179-185.

Czarnecki, D. (2014). The Incidence of Melanoma is Increasing in the Susceptible Young Australian Population. Acta Derm Venereol, 94(5), 539-41.

Ferdosi et al. (2016). Melanoma in Iran: A Retrospective 10-Year Study. Asian Pac J Cancer Prev., 17(6), 2751-5.

Guarneri, F., \& Guarneri, R. (2014) Cutaneous Melanoma and environmental factors: Only a matter of sun? Pigment Cell Melanoma Res., 27(1), 147-8.

Habif, T. (2011). Pre Malignant and Malignant Melanoma skin tumors. Skin Disease Diagnosis and Treatment habif (3th ed., pp. 509-535). New York.

Hamed Alharbi, A. H., Mousa, A., Alrashidi, R. N., Alighadaf, Gh., \& Aljohani, A. M. (2018). Awareness about scabies symptoms,transmission ways and prevention among population in Al-Madinah almunawarh, Saudi Arabia. Pharmacophore, 9(6), 1-10.

Hanjani et al. (2016). Epidemiology of MalignantMelanoma over a Thirty-two Year Period (1981-2013) in Southern Iran. Middle East J Cancer, 7(4), 199-202.

Hassanpour, S. E., Mahmoudvand, H., \& Roueintan, A. (2018). Investigating the Effect of Use of Dressing Separator Layer of Partial-thickness Skin Graft Donor Site Compared to Routine Method. Entomol Appl Sci Lett, 5(1), 36-42.

Kumar, V., Abbas, A., \& Aster, J. (2015). Robbins and cotran pathologic basis of disease (9th ed.). Philadelphia: Elsevier Saunders, 1143-1180.

Masoompour, S. M., Yarmohammadi, H., Rezaianzadeh, A., \& Lankarani, K. B. (2011). Cancer incidence in southern Iran, 1998-2002: Results of population-based cancer registry. Cancer Epidemiol, 35(5), e42-7. 
Moslehi, R., Zeinomar, N., \& Boscoe, F. P. (2018). Incidence of Cutaneous Malignant Melanoma in Iranian provinces and American states matchedon ultraviolet radiation exposure: An ecologic study. Environ pollut., 234, 699-706.

Natalie, H. M., \& Wen-Qing, L. (2017). In W. H. Ward \& J. M. Farma (Eds.), Cutaneous Melanoma: Etiology and Therapy. Brisbane (AU): Codon Publications, 1, 20.

Noorbala, M. T., Mohammadi, S., \& Noorbala, M. (2013). Cutaneous Malignant Melanoma in central Iran: A 20-year study. Ir Red Crescent Med J., 15(8), 690-4.

Odashiro et al. (2015). An Bras Dermatol. Melanoma inhibitory activity in Brazilian patients with Cutaneous Melanoma, 90(3), 327-32.

Qi et al. (2014). Type 2 Diabetes Mellitus and Risk of Malignant Melanoma: A Systematic Review and Meta-Analysis of Cohort Studies. Iranian J Public Health, 43(7), 857-66.

Rahnama, Z., Meymandi, S. S., \& Nasiri, N. (2010). Cutaneous Melanoma in a desert climate zone: A retrospective study of 125 cases. Int J Dermatol., 49(4), 406-9.

Razi, S., Rafiemanesh, H., Ghoncheh, M., Khani, Y., \& Salehiniya, H. (2015). Changing Trends of Types of Skin Cancer in Iran. Asian Pac J Cancer Prev., 16(12), 4955-8.

Sholih et al. (2019). Risk factors of Lung Cancer in Indonesia: A qualitative study. J Adv Pharm Edu Res, 9(2), 41-45.

Shrihari, T. G. (2018). Beta endorphins - novel holistic therapeutic approach to chronic inflammation associated cancer. International Journal of Pharmaceutical and Phytopharmacological Research, 8(5), 35-38.

Zavarei, M. (2018). Epithelial mesenchymal transision and cancer associated fibroblasts in the adenoid cystic adenocarcinoma: A literature review. Annals of Dental Specialty, 6(3), 357-362.

\section{Copyrights}

Copyright for this article is retained by the author(s), with first publication rights granted to the journal.

This is an open-access article distributed under the terms and conditions of the Creative Commons Attribution license (http://creativecommons.org/licenses/by/4.0/). 